\title{
Urbanskirche Schwäbisch Hall
}

\section{Warum die spätgotische Kanzel ursprünglich drei Brüstungsseiten, der Turm aber nur zwei Glocken hatte}

\author{
Von Hans Werner Hönes
}

Wer die Treppe zur quadratischen Kanzel an der Südwand des Chores in der Urbanskirche besteigt, dem fällt am Ende des Holzgeländers der grob abgeschlagene Ansatz einer steinmetzmäßig bearbeiteten Brüstungsseite des Kanzelkorbs auf. Die ursprünglich dritte Seite der mit einfachem Maßwerk versehenen Sandsteinbrüstungen der Kanzel hatte man entfernt, um hier einen Zugang zu schaffen. Zweifelsfrei war dies nicht ihr ursprünglicher Standort, zumal sich dahinter einst der Eingang zum Chor befand, der jetzt zugemauert ist. In seiner äusseren Nische fand später ein Kindergrabstein Platz.

\section{Wann kam überhaupt eine Kanzel in die Kirche und wo stand sie?}

Um 1450 erweiterte Schenk Friedrich V. das Schiff nach Norden. Dadurch lag der untere Teil der Westwand des Turms im Kircheninnern, sodass die Möglichkeit bestand, von der Kapelle im zweiten Turmgeschoss, die nur über eine Freitreppe auf der Nordseite zugänglich war, eine Verbindung zum Schiff herzustellen. Dies erreichte man durch Einzug einer bis zum Gewölbeansatz der Kapelle hochgeführten Trennwand (darüber blieb die alte Raumgröße erhalten) mit schmaler $55 \mathrm{~cm}$ breiter Türe zu einem dadurch geschaffenen schmalen Treppenflur auf der Südseite. Um diesen etwas zu verbreitern, verschwächte man die einen Meter dicke Turmwand in diesem Bereich auf eine Wandstärke von rund $35 \mathrm{~cm}$ !! Am 2,13 m tiefer liegenden unteren Ende der Treppe brach man in die Westwand des Turms eine $63 \mathrm{~cm}$ breite Rundbogentüre ${ }^{1}$. Beim Anlegen dieser Treppe wurde sogar ein Teil des Gewölbes über der Sakristei freigelegt. Die nun 2,10 m über dem Fußboden des Seitenschiffs liegende Türe dürfte der Zugang zur vermutlich damals beschafften Kanzel mit drei mit Maßwerk verzierten Kor-

1 H. W. Hönes: Urbanskirche Schwäbisch Hall - Bauliche Veränderungen und Instandsetzungen vom Mittelalter bis zur Neuzeit und kirchliche Nutzung von der Reformation bis zur Neuzeit. 2006. S. 19. 


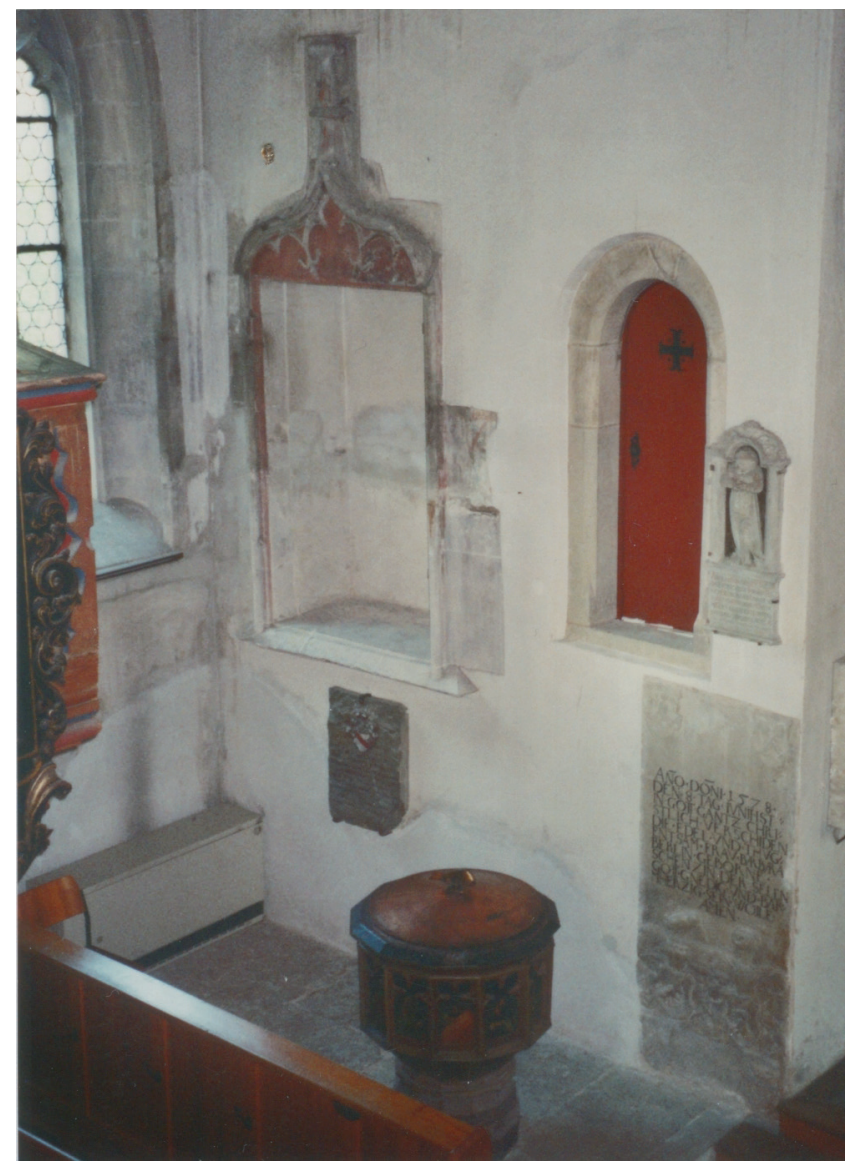

Westwand des Turms im Schiff mit Altarnische und Türe zur Turmkapelle

puswänden gewesen sein. Wandkanzeln dieser Art finden sich z. B. in Forchtenberg und Künzelsau, die Michael Kern zu Beginn des 17. Jahrhunderts schuf.

\section{Warum und wann musste die Kanzel dort entfernt werden?}

Hier hilft uns die Jahreszahl 1614, die am Pfosten der Nordempore aufgemalt ist, weiter. Damals wurden mehr Kirchenstühle benötigt, sodass man sich entschloss, die bereits vorhandene Westempore auf der Nordseite bis zur westlichen Turmwand weiterzuführen. Die Kanzel war also im Weg, wurde abgebrochen und auf die Südseite verlegt, wobei die südliche Chortüre zugemauert werden musste. Dieser Aktion fiel leider auch die spätgotische Umrahmung der Grablegung in 


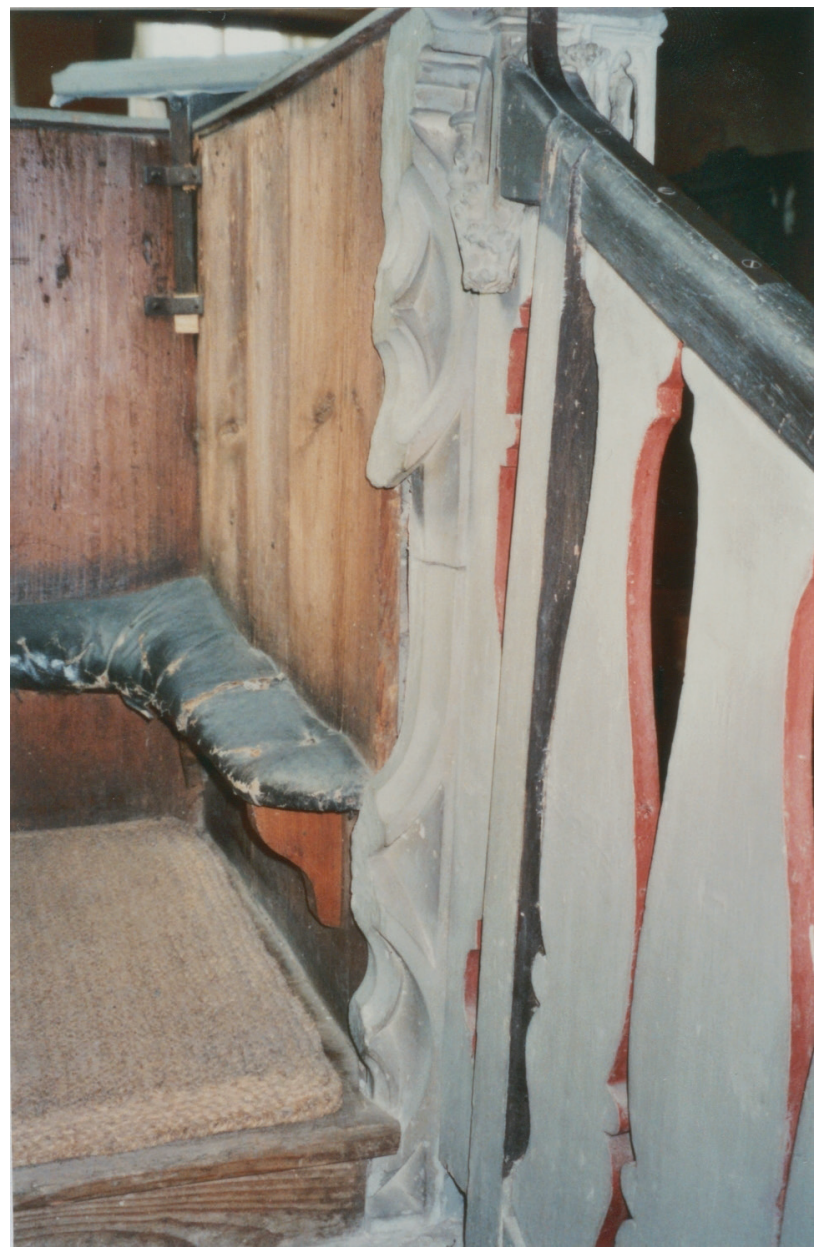

Rest der vermutlich bei der Umsetzung auf die Südseite entfernten dritten Seite der Kanzel

der Nordwand zum Opfer, die brutal durchschnitten und z.T. abgeschlagen wurde. Der sechseckige Kanzeldeckel stammt vermutlich ebenfalls aus dieser Zeit. Da die Kanzel vor einem Chorfenster steht, mußte dieser kunstvoll in der Fensternische aufgehängt werden. Er ist viel zu hoch angebracht und daher schalltechnisch völlig unwirksam. Mit seiner Sechseckform hat er auch keinerlei Bezug zur quadratischen Kanzel.

1961 verkürzte Architekt Dr. Krüger die Nordempore um vier Meter im Bereich des Turms, um das schöne Maßwerkfenster dort sichtbar zu machen und einen Platz für den Taufstein zu schaffen, der bis dahin vor dem Hochaltar stand. 


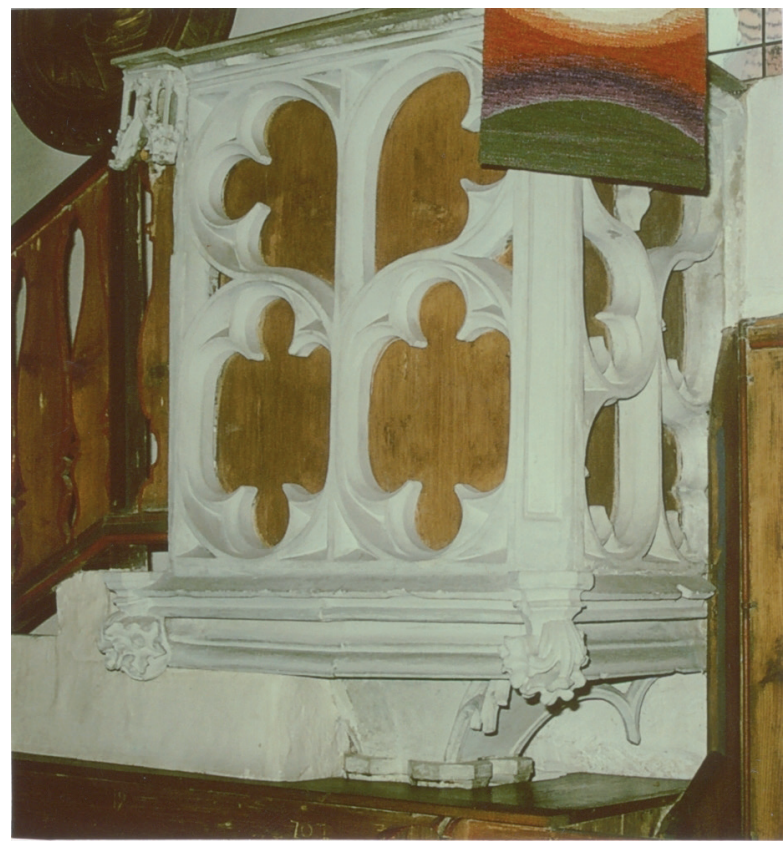

Spätgotische Kanzel

Gleichzeitig rekonstruierte er die ehemalige Rundbogentüre in der westlichen Turmwand, die seit 1614 zugemauert war. Bei der Generalrenovierung der Kirche 2011/12 wurde die dahinter liegende Treppe zur Turmkapelle, die sich in völlig ruinösem Zustand befand, wieder hergestellt. Da der einstige Zugang mit Aussentreppe auf der Nordseite nicht mehr vorhanden ist, kann die einstige Kapelle jetzt über dieses „Törchen“ erreicht werden, allerdings nur über eine Leiter!

\section{Beim Geläute auf dem Turm erhebt sich die Frage nach dem ursprüng- lichen Zustand. Waren es zwei oder drei Glocken?}

Die Antwort gibt ein Untersuchungsbericht von Glockengießer Heinrich Kurtz, Stuttgart, vom 13. November 1889. Darin stellt er fest, dass zwei Glocken vorhanden waren ${ }^{2}$ :

2 Hönes (wie Anm. 1); P. Glasbrenner / H.W. Hönes: Die Glocken von Schwäbisch Hall. 2002. S. 39 . 
„1. Glocke: unterer Durchmesser $82 \mathrm{~cm}$, Gewicht ca. $330 \mathrm{~kg}$. Diese Glocke ist gesprungen.

2. Glocke: unterer Durchmesser 67,5 cm, Gewicht ca.160 kg. Ton: D + 1/8.“ Nach dem Glockenatlas stammt die zweite von Stephan Bruncler und Johannes Arnold gegossene Glocke von 1688. Dieses geschätzte Gussdatum stimmt annähernd mit der Erstellung des Fachwerkgeschosses überein, mit dem eine größere Glockenstube geschaffen und dessen Holz 1697/98 geschlagen wurde. Das Zweiergeläute bestand also rund 200 Jahre.

Kurtz distanzierte sich in dem oben erwähnten Bericht von seinem ursprünglichen Plan, zwei Glocken von St. Michael, und zwar die H- und die E-Glocke, in die Urbanskirche umzuhängen (als Ersatz für die gesprungene). Er schlug nun vor, zwei neue Glocken zu beschaffen und zwar aus folgenden Gründen:

1.) Die beiden Glocken von St. Michael würden kein harmonisches Geläute ergeben.

2.) Die H-Glocke wäre für den Turm der Urbanskirche zu schwer.

3.) Der Glockenstuhl müsste umgebaut werden, da er zu eng sei.

4.) Das Material der gesprungenen Glocke reiche annähernd für die Herstellung einer $\mathrm{H}$ - und einer Fis-Glocke aus, sodass der Kostenaufwand relativ gering sei.

Am 13. Dezember 1889 beschloss der Stiftungsrat, zwei neue Glocken zu beschaffen. Die „Königl. Württembergische Regierung des Jagst-Kreises“ in Ellwangen hat diesem Vorhaben am 31. Januar 1890 zugestimmt mit der Bedingung, dass die Hälfte der Kosten aus den Neubaukapitalien dieser Kirche und zur Hälfte aus den laufenden Mitteln der Kirchenpflege bestritten werden sollten.

1917 mussten die beiden neuen Glocken jedoch abgenommen und bei der Ablieferungsstelle des städtischen Waaghauses abgeliefert werden. Für die erste Glocke mit $265 \mathrm{~kg}$ erhielt die Gemeinde 1.192,50 M Für die zweite Glocke mit $75 \mathrm{~kg}$ erhielt die Gemeinde $\quad 337,50 \mathrm{M}$ insgesamt also $1.530,00 \mathrm{M}$

Diese Glocken kamen nicht mehr zurück. Das Dreiergeläute bestand also nur 28 Jahre. Bei der Instandsetzung des leicht geneigten Fachwerkgeschosses entfernte man den dritten Glockenstuhl, der den Zugang zum Glockengeschoss stark behinderte, und stellte ihn beiseite. 
